\title{
Molecules Produced by Probiotics and Intestinal Microorganisms with Immunomodulatory Activity
}

\author{
Susana Delgado ${ }^{1,2}$, Borja Sánchez ${ }^{1,2}$, Abelardo Margolles ${ }^{1,2}$, Patricia Ruas-Madiedo ${ }^{1,2}$ (I) and \\ Lorena Ruiz ${ }^{1,2, *}$ \\ 1 Department of Microbiology and Biochemistry of Dairy Products, Dairy Research Institute of \\ Asturias (IPLA)-Spanish National Research Council (CSIC), Villaviciosa, 33300 Asturias, Spain; \\ sdelgado@ipla.csic.es (S.D.); borja.sanchez@csic.es (B.S.); amargolles@ipla.csic.es (A.M.); \\ ruas-madiedo@ipla.csic.es (P.R.-M.) \\ 2 Instituto de Investigación Sanitaria del Principado de Asturias (ISPA), Oviedo, 33011 Asturias, Spain \\ * Correspondence: lorena.ruiz@ipla.csic.es
}

Received: 7 January 2020; Accepted: 30 January 2020; Published: 1 February 2020

\begin{abstract}
Probiotics are live microorganisms that, when administered in adequate amounts, confer a health benefit on the host. The probiotic microorganisms most commonly used in the food and pharmacy industry belong to Lactobacillus and Bifidobacterium, and several strains of these genera have demonstrated beneficial attributes. In addition, some other intestinal bacteria inhabiting the human microbiota, such as Faecalibacterium prausnitzii and Akkermansia muciniphila, have recently been discovered and are able to display health-promoting effects in animal and human trials. The beneficial properties of probiotics have been known for a long time, although little is known about the molecular mechanisms and the molecules responsible for their effects. However, in recent years, advances in microbiome studies, and the use of novel analytical and molecular techniques have allowed a deeper insight into their effects at the molecular level. This review summarizes the current knowledge of some of the molecules of probiotics and other intestinal commensal bacteria responsible for their immunomodulatory effect, focusing on those with more solid scientific evidence.
\end{abstract}

Keywords: microbiota; microbiome; probiotics; immunomodulation; molecular effectors

\section{Introduction}

Some health-promoting effects of gut commensal, beneficial and probiotic microorganisms can be mediated through soluble factors (products or metabolic byproducts), secreted by live bacteria, or released after bacterial lysis. Precise identification of these biologically active compounds will enable a better formulation of microbiome-based biotherapeutics, and open up the possibility of administering purified biologically active fractions rather than whole live cells [1]. Besides, numerous other beneficial effects of gut microorganisms are mediated through their key role in the modification of dietary precursors within the gut ecosystem. These modifications can lead to the production of soluble bioactive fractions such as short chain fatty acids (SCFA), including butyrate, acetate and propionate, which have been correlated with health deterioration in the elderly $[2,3]$. Also, it has been suggested that some amino acid derivatives, such as indole, display lower fecal concentration levels in patients suffering from ulcerative colitis [4]. Indeed, using microbial bioactive compounds rather than live microorganisms could be particularly important when dealing with vulnerable immunocompromised or immunodeficient populations. Overall, these cellular or metabolic fractions can have immunomodulatory, antihypertensive, anti-proliferative and anti-oxidant activities, representing the mechanism of action for the health-promoting traits attributed to some gut commensals. 
Traditionally, the concept of health promotion through gut ecosystem modulation has relied either on the administration of live cells of gut commensals with probiotic attributes, usually belonging to a narrow range of microbial species, or in the administration of prebiotic substrates capable of sustaining such populations within the gut ecosystem [5]. However, recent evidence is leading to the inevitable evolution of the strategies available to modulate the gut ecosystem. The identification of the soluble mediators of the health-promoting effects of gut microbes implies that improvement in the well-functioning gut ecosystem and host well-being might be independent of probiotic cells viability, thus facilitating novel opportunities for gut microbiota-mediated health promotion [1]. This might be particularly important in the framework of recent investigations, which are pointing towards the existence of a much wider range of health-promoting commensal microorganisms within the healthy gut ecosystem than previously anticipated [6]. As such, current trends in the field are focusing their attention on the potential health-promoting traits of commensal bacterial species which do not fall into the traditional probiotic groups, Bifidobacterium and Lactobacillus, but into well-adapted gut microorganisms such as Faecalibacterium, Akkermansia, Ruminococcus and other Lachnospiraceae members, whose extreme oxygen sensitivity and tight adaptation to the gut ecosystem severely hampers their preparation as viable (food) supplements. Those microorganisms could be referred to as next-generation probiotics [6]. Identification of biologically active fractions from such microorganisms will undoubtedly open novel possibilities to exploit their health-promoting attributes, avoiding the technological and regulatory hassle of converting them into viable whole-cell supplements. However, despite the great advances that precise delineation of the biologically active fractions of gut commensals will have for the design of microbiota-based health promotion strategies, only a few cellular components or metabolites from gut commensals have been unequivocally associated with health promotion mechanisms up to date.

The present review summarizes current evidence on cellular and metabolic soluble fractions of gut commensals for which a health-promoting effect, mainly immunomodulation, has been attributed, including their metabolic action on selected dietary bioactive ingredients. Besides, it will discuss the possible exploitation of this knowledge to design novel gut microbiome-based biotherapeutics and food supplements capable of ameliorating an increasingly large range of health conditions. A summary of the immunomodulatory molecules and compounds discussed in this review is presented in Table 1.

\section{Proteinaceous Molecules with Immunomodulatory Activities}

Extracellular or surface-associated proteinaceous molecules from commensal gut microorganisms exert crucial functions in their interaction with the host, and represent important microbe-associated molecular patterns (MAMPs), leading to the activation of specific signalization pathways upon pattern recognition receptors (PRRs) recognition. For this reason, some of them have been identified as the molecular effectors of some health-promoting attributes mediated by probiotic and commensal microorganisms $[7,8]$. Indeed, specific extracellular and secreted proteins from commensal microorganisms are the primary target of intestinal IgA, whose main role is to monitor the commensal bacterial populations within the gut. In this context, up to six different extracellular proteins from Bifidobacterium longum, Bifidobacterium bifidum and Bifidobacterium animalis strains were recognized by pooled sera from healthy volunteers or inflammatory bowel disease (IBD) patients [9]. Also, levels of IgA antibodies developed against a cell-wall hydrolase from Lactobacillus rhamnosus GG were significantly higher in the IBD group, indicating that IBD patients appeared to have different immune response to food bacteria [9]. In the same way, remarkably, surface immunoreactive proteins were identified in 4 lactobacilli strains, including the presence of several moonlighting proteins, represented by proteins lacking any known secretory motif, but known to be located in the microbial surface [10].

In relation to the specific proteins from commensal microorganisms which might trigger immune effects in the host, pili-structures are common mediators of the immunomodulation exerted by various commensal species, including the classical lactobacilli or bifidobacterial groups. For instance, Lactococcus lactis heterologously expressing pili-proteins from B. bifidum associated with reduced IL10 
and increased tumor necrosis factor $\alpha(\mathrm{TNF} \alpha)$ in an in vivo mice model [11]; and co-administration of flagellin and Lactobacillus casei strain Shirota, enhanced IL12 production [12]. Besides, two secreted proteins from lactobacilli, p75 and p40, have been found capable of inhibiting cell apoptosis induced by proinflammatory states [13]. A novel secreted protein from L. rhamnosus GG, HM0539, has been deemed as being responsible for the protective effects exhibited by the corresponding producing strain on the intestinal barrier, enhancing intestinal mucin expression and preventing lipopolysaccharide (LPS) or TNF $\alpha$-induced intestinal barrier injury [14].

Recent investigations have revealed that, in addition to classical probiotic species, other gut commensal microorganisms frequently dominant in healthy populations and depleted in several disease population groups, can also interact with the host immune system in a beneficial way, and might thus represent promising next generation health-promoting microorganisms. In a few cases, proteinaceous determinants of their health-promoting attributes have also been identified. These include both homologues to proteins present in lactobacilli and bifidobacterial species, but also other specific novel proteins. For instance, pili-structures from Akkermansia muciniphila, a microorganism which has been attributed a critical role in the amelioration of metabolic syndrome and type- 2 diabetes, have also been identified as key mediators of the immune and gut barrier function [15]. Concerning other specific mediators of the effects exerted by other beneficial gut commensals, seven peptides secreted by Faecalibacterium prausnitzii, all belonging to a protein called the microbial anti-inflammatory molecule (MAM), showed anti-inflammatory properties both in vitro and in in vivo colitis models, inhibiting nuclear factor (NF)-kB pathways and reducing T-helper (Th)1 and Th2 responses [16]. Besides, immunoglobulin binding super antigenic proteins, IbpA and $\mathrm{Ibp} B$, have also been identified in Ruminococcus gnavus, a member of the taxon that defines one of the enterotypes that describes the gut microbiota inter-individual variability [17]. IpbA and IpbB expression have been associated with high IgA coating of the corresponding strain in vivo, as well as higher serum IgA levels [18]. Remarkably, about $40 \%$ of the analyzed gut metagenomes from healthy individuals from the United States and China presented these superantigenic proteins, yet their specific contribution to health and disease states remains to be elucidated.

Recent investigations have also delineated specific short peptide sequences, encrypted in larger surface-associated or extracellular proteins from commensal microorganisms, responsible for the observed immunomodulatory effects exerted by the producing strains. As an example, the STp peptide, a serine and threonine rich peptide included in one of the main extracellular proteins from Lactobacillus plantarum, was the first to be described as inducing an anti-inflammatory response in dendritic cells from IBD patients $[19,20]$. More recently, the development of proteomic databases of the gut microbiome has enabled the prediction of immunomodulatory potential of peptides encrypted in the gut commensals metaproteome [21]. Such an approach has led to the identification and validation of the immunomodulatory potential of two encrypted peptides, FR-16 and LR-17, included in proteins from B. longum DJO10A and Bacteroides fragilis YCH46, which exhibited a capacity to differentiate Th17 and Th22 differentiation pathways using immune cells models [7]. These works evidence that precise identification of specific proteins and/or encrypted peptides from gut commensals mediating immune responses in the host, will lead to the design of novel gut microbiota-based biotherapeutics.

\section{Exopolysaccharides and Immunomodulation}

The most external layer covering the surface of many bacteria is constituted by repeating units of monosaccharides, building a polymeric matrix of exopolysaccharides (EPSs) which can be loosely attached forming a slime structure, or be covalently linked as a capsule. Certain EPSs with specific characteristics, such as the zwitterionic (having both positive and negative charges) polysaccharides produced by Bac. fragilis, play a crucial role in the maintenance of the immune homeostasis at the intestinal level [22]. In fact, the presence of both charges is of pivotal relevance for activation of the immune response since this capability is lost when the polymers are modified to change the charge of the molecule. In Lactobacillus spp., the polymers having a single type of monosaccharide are known as 
homopolysaccharides ( $\alpha$-glucans, $\beta$-glucans or $\beta$-fructans). In this genus, as well as in Bifidobacterium spp., heteropolysaccharides, which are those having different monosaccharides (typically D-glucose, D-galactose and L-rhamnose), are also synthesized [23]. Both EPS types constitute a protective cover for the producing bacterium, but also act as an MAMP that will be recognized by different PRRs, thus inducing different responses in the host [24]. Little is known about the PRRs involved in the recognition of EPS synthesized by probiotics. It has been shown that specific $\beta$-glucans could act as ligands for certain C-type lectins (such as Dectin 1) located in the intestinal epithelium [25]; additionally, specific heteropolymers synthesized by bifidobacteria or lactobacilli can be recognized by TLR (toll like receptor) -4 [24,26,27].

Some of the health benefits exerted by probiotics have been attributed to the presence of EPS structures in the envelope surrounding the producing bacteria [23,28]. Immunomodulatory potential has been suggested for polymers synthesized by lactic acid bacteria and bifidobacteria having specific characteristics, such as high molar mass (more than $10^{6} \mathrm{Da}$ ), or the presence of a negative charge in the molecule $[29,30]$; however, the mechanism by which these specific bacterial EPSs trigger immune response remains to be elucidated. More recently, it has also been indicated that the presence of galactose in the EPSs synthesized by Lactobacillus reuteri strains enhanced their anti-inflammatory effects on macrophages, although the scarce number of polymers analyzed limited a conclusive statement [31]. Additionally, most of the evidence on the immunomodulation capacity of probiotics EPS was based on in vitro observations, mainly using cultures of peripheral mononuclear cells (PBMCs), dendritic cells, or macrophage cell lines, after checking the pattern of cytokines released [32]. Nonetheless, in recent years, the protective effect of EPS-producing probiotics on immune compromised states has also been studied in vivo using animal experimental models. F. prausnitzii, one of the most abundant members of Firmicutes phylum in the colon of healthy individuals, is underrepresented in patients with IBD; therefore, it has been proposed as an anti-inflammatory next-generation probiotic. The EPS matrix produced by this species seems to be directly correlated with its immunomodulation capability as was demonstrated after an intra-rectal administration of the purified EPS in a model of acute ulcerative colitis (DSS-induced) BALB/c mice. The in vitro analyses with immune cells suggested that the anti-inflammatory potential of the EPS synthesized by F. prausnitzii HTF-F was mediated by production of IL-12 and IL-10 in antigen presenting cells in a TLR-2-dependent manner [33]. In a similar way, the oral administration of B. animalis subsp. lactis Balat_1410 ${ }^{\mathrm{S} 89 \mathrm{~L}}$ to DSS-induced colitis C57BL/6J mice reduced the damage (disease activity index) caused by this chemical agent. This strain produced a "ropy" EPS, having a high molar mass (about $10^{6} \mathrm{Da}$ ) with a high content of rhamnose (more than 50\%), and formed a long filament when the colony growing on the surface of agar-culture was touched with an inoculation loop. The comparison of the ropy strain with its non-ropy isogenic counterpart, showed that the attenuation of the damage caused by DSS could be related with the capability of the first to induce an increase in the $\mathrm{T}$ regulatory (Treg) cell number of mesenteric lymphoid nodes, which could lead to a reduction in the inflammatory state at the mucosal level [34]. In fact, previous ex vivo experiments carried out with these two isogenic B. animalis subsp. lactis strains showed the high anti-inflammatory potential of the ropy EPS-producing strain. This ropy Balat_1410 ${ }^{\text {S9L }}$ strain favored a significant increase of IL-10 by human PBMCs after co-cultivation with an UV-inactivated bifidobacterial suspension; similarly, co-incubation with colonic biopsy specimens significantly reduced the production of TNF $\alpha$ by the tissue [35]. Thus, B. animalis subsp. lactis strains having a ropy phenotype, denoting the production of EPS with specific traits, could be proposed as probiotic candidates to attenuate intestinal inflammatory episodes. More recently, similar in vivo works corroborate these findings with different EPS-producing bifidobacteria. The EPS synthesized by Bifidobacterium adolescentis IF1-03 was able to modulate the macrophage-regulated Treg/Th17 axis and, therefore, protect DSS-colitis mice [36]; and the EPS-producing B. longum subsp. longum YS108R alleviated the DSS-induced colitis by modulating inflammatory cytokines, reinforcing the mucosal barrier and also reverting the microbial dysbiosis caused by this chemical agent [37]. 
The results briefly summarized above, demonstrating the immune modulating capability of EPS synthesis by Gram-positive probiotics, show a promising way of intervention to attenuate intestinal inflammatory states. Additionally, the viability of the producing bacterium is not required to exert a beneficial effect and the EPS layer covering the bacterial surface is resistant to the harsh conditions of the gastrointestinal tract, thus allowing it to arrive intact to the colon [38]. Therefore, the use of EPS-producing strains from difficult-to-handle bacteria, such as, for example, those that lost viability in the presence of oxygen, could be a solution to overcome the technological challenge that currently supposes the production of some next generation probiotics.

\section{Other Cell-Wall Components}

In addition to EPS and proteinaceous components that have already been discussed in previous sections, the biological layers surrounding the bacterial cell membrane are a reservoir of other macromolecules with immunomodulatory activity. Among them, the cell wall of Gram-positive bacteria has been the most studied and numerous articles show that cell wall fractions display different bioactive functions. For example, exposure of dendritic cells to cell wall extracts from B. bifidum trigger Treg differentiation [39], and it has been shown that the immune stimulatory properties of L. plantarum in macrophage cells are largely due to cell wall crude fractions [40]. Perhaps the most studied immune-active molecules contained within the cell wall are teichoic and lipoteichoic acids (TAs and LTAs, respectively). In this regard, very little information is available about these molecules in Bifidobacterium and few papers have described the role of bifidobacterial LTAs in immune responses [41]. On the contrary, some pioneering works show that the TA and LTA of Lactobacillus species can have a potent effect on the immune system, and their role has been elucidated using in vitro and animal models. Grangette et al. [42] evaluated the role of TAs in the interaction between L. plantarum NCIMB8826 and the immune system by analyzing the anti-inflammatory properties of a mutant affected in the TA biosynthesis. The deficient mutant, having a lower content of alanine in its TA, was able to increase IL-10 production and dramatically reduce secretion of pro-inflammatory cytokines by PBMCs and monocytes, as compared with the wild type strain. Furthermore, the mutant was more protective in a murine colitis model. The results indicated that LTA of L. plantarum can modulate pro-inflammatory or anti-inflammatory responses. Subsequent studies showed other immunomodulatory features of L. plantarum LTA, such as the down-regulation of Shigella flexneri peptidoglycan-induced inflammation [43], or the suppression of LPS-mediated inflammation [44], among other effects. LTA function has also been studied in L. rhamnosus GG (LGG), one of the most studied probiotics [45]. Mice treated with an LTA deficient mutant of LGG showed an improvement of colitic parameters compared to LGG wild-type-treated mice; an effect which was likely mediated by LTA-TLR2 interactions [46]. Also, Claes and coworkers [47] showed that LTA of LGG is an MAMP with pro-inflammatory activities via TLR2/6 interaction. Furthermore, a recent work demonstrated that LTA of LGG primes the epithelial stem cell niche to protect epithelial stem cells from radiotherapy, by promoting an adaptive immune signaling cascade [48]. The beneficial effects of LTA have also been demonstrated in the species Lactobacillus paracasei. Its LTA enhances mucin expression by modulating the TLR-2 pathway, and reduces leaky gut and inflammation [49]. Overall, current evidence indicates that TAs and LTAs from probiotic bacteria interact with the host to play important physiological roles as potent immune modulators [50].

\section{Microbial Metabolites with Immune Function}

Intestinal microorganisms regulate the host immune system, in part, by producing metabolites acting via host receptors and other target molecules. Immune cells express receptors specific for metabolites, such as aryl hydrocarbon receptor precursor (AhR), pregnane $X$ receptor (PXR) and farnesoid X receptor (FXR) among others, or less specific receptors like cell surface G-protein-coupled receptors (GPCRs) as an example [51]. Microbial metabolites can have a bidirectional function to 
promote both tolerance and immunity. Some of the microbial metabolites with immunomodulatory functions are discussed next.

\section{1. -Short-Chain Fatty Acids}

The microbial metabolites better exemplifying this are the short-chain fatty acids (SCFAs) acetate (C2), propionate (C3) and butyrate (C4), produced as the result of bacterial carbohydrate fermentation in the colon [52]. These SCFAs act on leukocytes and endothelial cells through at least two mechanisms: activation of GPCRs receptors and inhibition of histone deacetylase (HDAC) [53]; however, the production of these SCFAs differs greatly among the intestinal members. Acetate is generated by many genera of intestinal microorganisms, including Bifidobacterium spp. Acetate released in the gut is used as substrates for other microbial gut fermenters, mainly butyrate and propionate producers belonging to the clostridial cluster IV and XIVa [54]. The production of these two major SCFA metabolites has been shown to have anti-inflammatory effects and promote and regulate the colonic Treg cells pool [55]. In particular, butyrate, as an epigenetic regulator of gene expression, acts on both DNA methylation and histone hyperacetylation [56]. By inhibiting histone deacetylation, butyrate acts in the differentiation of Treg cells, increasing the expression of the Treg marker Foxp3 ${ }^{+}$[57]. Also, acetate increases the acetylation of the Foxp3 promotor. Among the SCFAs, butyrate is the most potent HDAC inhibitor and acetate is the least potent [58]. Propionate, which is primarily produced by Bacteroidetes and some Firmicutes members of the intestinal microbiota mainly via the succinate metabolic pathway, has also been described as educating dendritic cells to achieve high phagocytic capacity and affect Th2 cell responses [59].

As previously mentioned, SCFAs also activate several GPCRs and, probably, the best-characterized are GPR43, GPR41 and GPR109A. GPR43 and GPR109A appear to be important for gut homeostasis, and both are expressed by intestinal epithelial cells, but not by T- and B-immune cells [60]. Some other immune populations, such as dendritic cells and inflammatory leukocytes (such as neutrophils and macrophages), express these GPR43 and GPR109A receptors at variable levels [58]. However, the study performed by Trompette and colleagues [59] proposes the effects of propionate on allergic inflammation to be dependent on GPR41, but not the GPR43 receptor. This is one of the reports showing the effect of increased levels of SCFAs and activity of their receptors GPCRs on enhancing oral tolerance and protecting against allergy [59,61]. The GPR109A receptor has recently emerged as a major regulator of gut homeostasis; this binds butyrate, but also the tryptophan metabolite nicotinic acid that will be described in the following section.

In addition to the interaction with different receptors, indirect evidence suggests that SCFAs might also promote the secretion of IgA by B immune cells [62]. Besides, the ability of SCFAs to inhibit the NF- $\mathrm{B}$ is already known and SCFAs have been reported to reduce production of inflammatory chemokines and cytokines such as TNF $\alpha$, IL-6, and interferon- $\gamma$ (IFN- $\gamma$ ) [53]. The anti-inflammatory effects of SCFAs on chemotaxis and leukocyte recruitment have been documented [63].

Unlike what happens with the three main intestinal SCFAs acetate, propionate and butyrate, little is known about the immunomodulatory effects of other SCFAs like the branched chain fatty acids (BCFAs) isobutyric and isovaleric acids, which are more related to microbial catabolism of proteins [52]. However, they are also reported in literature as HDAC inhibitors; therefore, their function in regulating host cells is expected to be similar to that of butyrate [51].

\section{2. -Compounds Derived from Protein Degradation}

The gut microbiota can determine to what extent dietary proteins are converted into other active metabolites, such as BCFAs, or different nitrogen containing compounds which could play a major role in the prevention of inflammatory diseases and are highlighted for their interaction with the immune system [58].

Other microbial metabolites from the breakdown of proteins are indolic compounds, mainly derived from aromatic amino acids like tryptophan. Tryptophan is degraded to skatole (3-methylindole) 
and other indoles by microbial degradation in the intestine with diverse gut microorganisms, such as lactobacilli [58]. The bioactive indole-3-aldehyde, indole-3-propionato and indole-3-acetic acid are products of the bacterial metabolism of tryptophan that affect the intestinal barrier integrity and immune cells activity through the activation of PXR and AhR receptors $[64,65]$. L. reuteri is one of the tryptophanase-positive bacteria that generate these indole metabolites and can stimulate AhR activity suppressing pro-inflammatory activities $[65,66]$. Other gut members such as Peptostreptococcus produce 3-indoleacrylic acid (IA) from tryptophan which promotes epithelial barrier function and mitigates inflammatory responses [67]. In fact, the metabolism of tryptophan has been related to allergy through its degradation via the immune-regulatory enzyme indoleamine 2,3-dioxygenase-1 (IDO-1), which is activated by the IFN- $\gamma$ [68]. IFN- $\gamma$ is a strong inducer of IDO- 1 , which degrades this essential amino acid as part of an immunoregulatory strategy to avoid over-activation of the immune system [68]. IDO activity is linked to suppression of T cell responses, promotion of Treg cells and immune tolerance [69]. Other reports exist indicating that D-tryptophan from probiotic bacteria can decrease Th2 response in the gut and lung, influencing allergic reactions [70,71]. Moreover, tryptophan is degraded endogenously via this IDO enzyme to kynurenin (an AhR agonist) which, after binding to Ahr receptors, promotes the production of important mediators for gut homeostasis [58]. Other tryptophan metabolites, including kynurenic acid and niacin, also target metabolite-sensing GPCRs, such as GPR35 and GPR109A. From these, GPR109A binds the SCFA butyrate but also the tryptophan metabolite nicotinic acid which is known to have anti-inflammatory properties [58]. It is necessary to clarify that all these kyneurines are endogenous (host) tryptophan metabolites different from the bacterial tryptophan metabolites (indole metabolites) [72]. 
Table 1. Immunomodulatory molecules and compounds discussed in this review.

\begin{tabular}{|c|c|c|c|}
\hline Species & Molecule & Effect & Reference \\
\hline \multicolumn{4}{|c|}{ Peptides and proteins } \\
\hline Bifidobacterium sp. & Pili & $\uparrow T N F \alpha, \downarrow I L 10$ & [11] \\
\hline Several species & Flagellin & $\uparrow I L 12$ & {$[12]$} \\
\hline Lactobacillus sp. & p75 and p40 & $\downarrow$ Cell apoptosis & [13] \\
\hline Lactobacillus rhamnosus & HM0539 & $\downarrow$ LPS- or TNF $\alpha$-mediated barrier injury & {$[14]$} \\
\hline Akkermansia muciniphila & Pili-structures & Amelioration of metabolic syndrome and type- 2 diabetes & {$[15]$} \\
\hline Faecalibacterium prautsnitzii & MAM & $\downarrow N F-k B$ pathways, $\downarrow$ Th1 and Th2 responses & [16] \\
\hline Ruminococcus gnavus & $\mathrm{Ibp} A$ and $\mathrm{IpB}$ & Targets for IgA coating & [18] \\
\hline Lactobacillus plantarum & $\mathrm{STp}$ & $\uparrow \operatorname{IL} 10, \downarrow$ IL12 & {$[19,20]$} \\
\hline Bifidobacterium longum & FR-16 & $\uparrow$ Th17, Th22 responses & [7] \\
\hline Bacteroides fragilis & LR-17 & $\uparrow$ Th17, Th22 responses & [7] \\
\hline \multicolumn{4}{|c|}{ Exopolysaccharides } \\
\hline Bacterioides fragilis & Zwitterionic & Homeostatic molecule & [22] \\
\hline Several species & $\beta$-glucans & C-type lectin ligands & [25] \\
\hline Bifidobacteria/Lactobacilli & Heteropolymers & TLR-4 ligands & {$[24,27]$} \\
\hline Bifidobacteria/Lactobacilli & High Molar EPS & Immunomodulatory & [29] \\
\hline Lactobacillus reuteri & EPS & Anti-inflammatory & [31] \\
\hline Faecalibacterium prausnitzii & EPS & $\uparrow$ IL-12 and IL-10; TLR-2-mediated & [33] \\
\hline Bifidobacterium animalis subsp. lactis & Ropy EPS & $\uparrow I L 10$ & [35] \\
\hline Bifidobacterium animalis subsp. lactis & Ropy EPS & $\uparrow$ Treg response & {$[34]$} \\
\hline Bifidobacterium adolescentis & EPS & Treg/Th17 response modulation & [36] \\
\hline Bifidobacterium longum & EPS & Inflammatory cytokine modulation, mucosal barrier reinforcement & [37] \\
\hline \multicolumn{4}{|c|}{ Other cell wall components } \\
\hline Bifidobacterium bifidum & Cell wall extract & Treg differentiation & [39] \\
\hline Lactobacillus plantarum & Cell wall extract & Immunostimulatory & [40] \\
\hline Lactobacillus plantarum & Teichoic acids & IL10 production modulation & [42] \\
\hline Lactobacillus plantarum & Lipoteichoic acids & Suppression of LPS-mediated inflammation & {$[44]$} \\
\hline Lactobacillus rhamnosus & Lipoteichoic acids & Proinflammatory, TLR-2/6 ligand & {$[46,47]$} \\
\hline Lactobacillus rhamnosus & Lipoteichoic acids & Radiotherapy protection & {$[48]$} \\
\hline Lactobacillus paracasei & Lipoteichoic acids & $\downarrow$ Leaky gut and inflammation & [49] \\
\hline
\end{tabular}


Table 1. Cont.

\begin{tabular}{|c|c|c|c|}
\hline Species & Molecule & Effect & Reference \\
\hline \multicolumn{4}{|c|}{ Microbial metabolites } \\
\hline Several species & Short-chain fatty acids & Activation of GPCRs $\downarrow$ histone deacetylase & [53] \\
\hline Several species & Short-chain fatty acids & NF- $\kappa B$ inhibition, $\uparrow$ IgA secretion, $\downarrow$ pro-inflammatory cytokines, $\uparrow$ leukocyte recruitment & {$[63]$} \\
\hline Several species & Propionate, butyrate & Anti-inflammatory, $\uparrow$ Treg response & [55] \\
\hline Several species & Butyrate & $\downarrow$ histone deacetylase, $\uparrow$ Treg & [57] \\
\hline Several species & Propionate & Affects Th2 response & [59] \\
\hline Several species & $\begin{array}{l}\text { Branched-chain fatty acids } \\
\text { Indole-3-aldehyde, }\end{array}$ & Inhibition of histone deacetylase & [51] \\
\hline Several species & $\begin{array}{l}\text { indole-3-propionate and } \\
\text { indole-3-acetic acid }\end{array}$ & $\uparrow$ Barrier integrity and immune cell function & {$[64,65]$} \\
\hline Peptostreptococcus sp. & 3-indoleacrylic acid & $\uparrow$ Epithelial barrier and immune cell function & [67] \\
\hline Several species & D-tryptophan & $\downarrow$ Th2 response & {$[70,71]$} \\
\hline Several species & $\begin{array}{l}\text { Kynurenic acid, niacin, } \\
\text { nicotinic acid }\end{array}$ & Gut homeostasis regulators, anti-inflammatory & {$[58]$} \\
\hline Several species & $\begin{array}{l}\text { Glutamine, histidine and } \\
\text { glycine- derived metabolites }\end{array}$ & Influence gut homeostasis and immune cell function & {$[70]$} \\
\hline
\end{tabular}




\section{Future Perspectives}

Immunomodulation is one of the most studied characteristics of probiotic microorganisms. The ability to stimulate our immune function has especially been studied in lactobacilli and bifidobacteria, where some molecules responsible for beneficial effects (such as surface proteins and EPS) have been characterized. However, currently, the scientific community has a variety of novel methodologies that allow the study of the probiotic-mediated immunomodulation from novel perspectives. The new techniques used in microbiomic studies [73], genomic editing such as CRISPR-Cas [74], and cell and molecular biology [75], facilitate much more efficiently the unraveling of the role of the molecules and pathways responsible for the mechanisms of action of probiotics. This will lead to the selection of probiotics with activities aimed at personalized treatments, based on solid knowledge of their effector molecules.

Author Contributions: S.D., B.S., A.M., P.R.-M. and L.R. wrote different sections of the manuscript and reviewed the final version of the manuscript. All authors have read and agree to the published version of the manuscript.

Funding: Funding in our group is supported by the grants IDI/2018/000236 from the Principality of Asturias, AGL2016-78311-R (AEI/FEDER UE) from the Ministry of Economy and Competitiveness (MINECO), and RTI2018-096339-B-I00 and RTI2018-095021-J-I00 (MCIU/AEI/FEDER, UE).

Conflicts of Interest: S.D., B.S. and A.M are co-founders and members of the Scientific Advisory Board of Microviable Therapeutics S.L.

\section{References}

1. Aguilar-Toalá, J.E.; Garcia-Varela, R.; Garcia, H.S.; Mata-Harod, V.; González-Córdova, A.F.; Vallejo-Cordoba, B.; Hernández-Mendoza, A. Postbiotics: An evolving term within the functional foods field. Trends Food Sci. Tech. 2018, 75, 105-114. [CrossRef]

2. Klemashevich, C.; Wu, C.; Howsmon, D.; Alaniz, R.C.; Lee, K.; Jayaraman, A. Rational identification of diet-derived postbiotics for improving intestinal microbiota function. Curr. Opin. Biotechnol. 2014, 26, 85-90. [CrossRef]

3. Morrison, D.J.; Preston, T. Formation of short chain fatty acids by the gut microbiota and their impact on human metabolism. Gut Microbes 2016, 7, 189-200. [CrossRef]

4. Agus, A.; Planchais, J.; Sokol, H. Gut Microbiota Regulation of Tryptophan Metabolism in Health and Disease. Cell Host Microbe 2018, 23, 716-724. [CrossRef]

5. Markowiak, P.; Śliżewska, K. Effects of Probiotics, Prebiotics, and Synbiotics on Human Health. Nutrients 2017, 9, 1021. [CrossRef] [PubMed]

6. O'Toole, P.W.; Marchesi, J.R.; Hill, C. Next-generation probiotics: The spectrum from probiotics to live biotherapeutics. Nat. Microbiol. 2017, 2, 17057. [CrossRef] [PubMed]

7. Hidalgo-Cantabrana, C.; Moro-García, M.A.; Blanco-Míguez, A.; Fdez-Riverola, F.; LourençO, A.; Alonso-Arias, R.; Sánchez, B. In Silico Screening of the Human Gut Metaproteome Identifies Th17-Promoting Peptides Encrypted in Proteins of Commensal Bacteria. Front. Microbiol. 2017, 8, 1726. [CrossRef] [PubMed]

8. Ruiz, L.; Delgado, S.; Ruas-Madiedo, P.; Margolles, A.; Sánchez, B. Proteinaceous Molecules Mediating Bifidobacterium-Host Interactions. Front. Microbiol. 2016, 7, 1193. [CrossRef] [PubMed]

9. Hevia, A.; López, P.; Suárez, A.; Jacquot, C.; Urdaci, M.C.; Margolles, A.; Sánchez, B. Association of levels of antibodies from patients with inflammatory bowel disease with extracellular proteins of food and probiotic bacteria. BioMed Res. Int. 2014, 2014, 351204. [CrossRef] [PubMed]

10. Górska, S.; Buda, B.; Brzozowska, E.; Schwarzer, M.; Srutkova, D.; Kozakova, H.; Gamian, A. Identification of Lactobacillus proteins with different recognition patterns between immune rabbit sera and nonimmune mice or human sera. BMC Microbiol. 2016, 16, 17. [CrossRef]

11. Turroni, F.; Serafini, F.; Foroni, E.; Duranti, S.; O'Connell Motherway, M.; Taverniti, V.; Mangifesta, M.; Milani, C.; Viappiani, A.; Roversi, T.; et al. Role of sortase-dependent pili of Bifidobacterium bifidum PRL2010 in modulating bacterium-host interactions. Proc. Natl. Acad. Sci. USA 2013, 110, 11151-11156. [CrossRef] [PubMed] 
12. Kaji, R.; Kiyoshima-Shibata, J.; Tsujibe, S.; Nanno, M.; Shida, K. Short communication: Probiotic induction of interleukin-10 and interleukin-12 production by macrophages is modulated by co-stimulation with microbial components. J. Dairy Sci. 2018, 101, 2838-2841. [CrossRef] [PubMed]

13. Yan, F.; Cao, H.; Cover, T.L.; Whitehead, R.; Washington, M.K.; Polk, D.B. Soluble proteins produced by probiotic bacteria regulate intestinal epithelial cell survival and growth. Gastroenterology 2007, 132, 562-575. [CrossRef]

14. Gao, J.; Li, Y.; Wan, Y.; Hu, T.; Liu, L.; Yang, S.; Gong, Z.; Zeng, Q.; Wei, Y.; Yang, W.; et al. A Novel Postbiotic from Lactobacillus rhamnosus GG with a Beneficial Effect on Intestinal Barrier Function. Front. Microbiol. 2019, 10, 477. [CrossRef]

15. Ottman, N.; Reunanen, J.; Meijerink, M.; Pietilä, T.E.; Kainulainen, V.; Klievink, J.; Huuskonen, L.; Aalvink, S.; Skurnik, M.; Boeren, S.; et al. Pili-like proteins of Akkermansia muciniphila modulate host immune responses and gut barrier function. PLOS ONE 2017, 12, e0173004. [CrossRef]

16. Breyner, N.M.; Michon, C.; de Sousa, C.S.; Vilas Boas, P.B.; Chain, F.; Azevedo, V.A.; Langella, P.; Chatel, J.M. Microbial Anti-Inflammatory Molecule (MAM) from Faecalibacterium prausnitzii Shows a Protective Effect on DNBS and DSS-Induced Colitis Model in Mice through Inhibition of NF-кB Pathway. Front. Microbiol. 2017, 8, 114. [CrossRef]

17. Arumugam, M.; Raes, J.; Pelletier, E.; Le Paslier, D.; Yamada, T.; Mende, D.R.; Fernandes, G.R.; Tap, J.; Bruls, T.; Batto, J.M.; et al. Enterotypes of the human gut microbiome. Nature 2011, 473, 174-180. [CrossRef]

18. Bunker, J.J.; Drees, C.; Watson, A.R.; Plunkett, C.H.; Nagler, C.R.; Schneewind, O.; Eren, A.M.; Bendelac, A. B cell superantigens in the human intestinal microbiota. Sci. Transl. Med. 2019, 11, eaau9356. [CrossRef]

19. Al-Hassi, H.O.; Mann, E.R.; Sanchez, B.; English, N.R.; Peake, S.T.; Landy, J.; Man, R.; Urdaci, M.; Hart, A.L.; Fernandez-Salazar, L.; et al. Altered human gut dendritic cell properties in ulcerative colitis are reversed by Lactobacillus plantarum extracellular encrypted peptide STp. Mol. Nutr. Food Res. 2014, 58, 1132-1143. [CrossRef]

20. Bernardo, D.; Sánchez, B.; Al-Hassi, H.O.; Mann, E.R.; Urdaci, M.C.; Knight, S.C.; Margolles, A. Microbiota/host crosstalk biomarkers: Regulatory response of human intestinal dendritic cells exposed to Lactobacillus extracellular encrypted peptide. PLoS ONE 2012, 7, e36262. [CrossRef]

21. Blanco-Míguez, A.; Gutiérrez-Jácome, A.; Fdez-Riverola, F.; Lourenço, A.; Sánchez, B. MAHMI database: A comprehensive MetaHit-based resource for the study of the mechanism of action of the human microbiota. Database (Oxford) 2017, 2017, baw157.

22. Round, J.L.; Lee, S.M.; Li, J.; Tran, G.; Jabri, B.; Chatila, T.A.; Mazmanian, S.K. The Toll-Like Receptor 2 pathway establishes colonization by a commensal of the human microbiota. Science 2011, 332, 974-977. [CrossRef] [PubMed]

23. Hidalgo-Cantabrana, C.; Sánchez, B.; Milani, C.; Ventura, M.; Margolles, A.; Ruas-Madiedo, P. Genomic overview and biological functions of exopolysaccharide biosynthesis in Bifidobacterium spp. Appl. Environ. Microbiol. 2014, 80, 9-18. [CrossRef] [PubMed]

24. Castro-Bravo, N.; Margolles, A.; Wells, J.; Ruas-Madiedo, P. Exopolysaccharides synthesized by Bifidobacterium animalis subsp. lactis interact with TLR4 in intestinal epithelial cells. Anaerobe 2019, 56, 98-101. [PubMed]

25. Kamiya, T.; Tang, C.; Kadoki, M.; Oshima, K.; Hattori, M.; Saijo, S.; Adachi, Y.; Ohno, N.; Iwakura, Y. $\beta$-glucans in food modify colonic microflora by inducing antimicrobial protein, calprotectin, in a Dectin-1-induced-IL-17F-dependent manner. Mucosal Immunol. 2018, 11, 763-773. [CrossRef] [PubMed]

26. Castro-Bravo, N.; Wells, J.M.; Margolles, A.; Ruas-Madiedo, P. Interactions of surface exopolysaccharides from Bifidobacterium and Lactobacilus within the intestinal environment. Front. Microbiol. 2018, 9, 2426. [CrossRef]

27. Kanmani, P.; Albarracin, L.; Kobayashi, H.; Iida, H.; Komatsu, R.; Kober, A.K.M.H.; Ikeda-Ohtsubo, W.; Suda, Y.; Aso, H.; Makino, S.; et al. Exopolysaccharides from Lactobacillus delbrueckii OLL1073R-1 modulate innate antiviral immune response in porcine intestinal epithelial cells. Mol. Immunol. 2018, 93, 253-265. [CrossRef]

28. Caggianiello, C.; Kleerebezem, M.; Spano, G. Exopolysaccharides produced by lactic acid bacteria: From health-promoting benefits to stress tolerance mechanisms. Appl. Microbiol. Biotechnol. 2016, 100, 3877-3886. [CrossRef] 
29. Hidalgo-Cantabrana, C.; López, P.; Gueimonde, M.; de los Reyes-Gavilán, C.G.; Suárez, A.; Margolles, A.; Ruas-Madiedo, P. Immune modulation capability of exopolysaccharides synthesised by lactic acid bacteria and bifidobacteria. Probiotics Antimicrob. Prot. 2012, 4, 227-237.

30. Sato, T.; Nishimura-Uemura, J.; Shimosato, T.; Kawai, Y.; Kitazawa, H.; Saito, T. Dextran from Leuconostoc mesenteroides augments immunostimulatory effects by the introduction of phosphate groups. J. Food Prot. 2004, 67, 1719-1724. [CrossRef]

31. Chen, Y.C.; Wu, Y.J.; Hu, C.Y. Monosaccharide composition influence and immunomodulatory effects of probiotic exopolysaccharides. Int. J. Biol. Macromol. 2019, 133, 575-582. [CrossRef] [PubMed]

32. Górska, S.; Sandstrőm, C.; Wojas-Turek, J.; Rossowska, J.; Pajtasz-Piasecka, E.; Brzozowska, E.; Gamian, A. Structural and immunomodulatory differences among lactobacilli exopolysaccharides isolated from intestines of mice with experimentally induced inflammatory bowel disease. Sci. Rep. 2016, 6, 37613. [CrossRef] [PubMed]

33. Rossi, O.; Khan, M.T.; Schwarzer, M.; Hudcovic, T.; Srutkova, D.; Duncan, S.H.; Stolte, E.H.; Kozakova, H.; Flint, H.J.; Samsom, J.N.; et al. Faecalibacterium prausnitzii strain HTF-F and its extracellular polymeric matrix attenuate clinical parameters in DSS-induced colitis. PLoS ONE 2015, 10, e0123013. [CrossRef]

34. Hidalgo-Cantabrana, C.; Algieri, F.; Rodriguez-Nogales, A.; Vezza, T.; Martínez-Camblor, P.; Margolles, A.; Ruas-Madiedo, P.; Gálvez, J. Effect of a ropy exopolysaccharide-producing Bifidobacterium animalis subsp. lactis strain orally administered on DSS-induced colitis mice Model. Front. Microbiol. 2016, 7, 868. [CrossRef] [PubMed]

35. Hidalgo-Cantabrana, C.; Sánchez, B.; Álvarez-Martín, P.; López, P.; Martínez-Álvarez, N.; Delley, M.; Martí, M.; Varela, E.; Suárez, A.; Antolín, M.; et al. A single mutation in the gene responsible for the mucoid phenotype of Bifidobacterium animalis subsp. lactis confers surface and functional characteristics. Appl. Environ. Microbiol. 2015, 81, 7960-7968. [CrossRef] [PubMed]

36. Yu, R.; Zuo, F.; Ma, H.; Chen, S. Exopolysaccharide-producing Bifidobacterium adolescentis strains with similar adhesion property induce differential regulation of inflammatory immune response in Treg/Th17 axis of DSS-colitis mice. Nutrients 2019, 11, 782. [CrossRef]

37. Yan, S.; Yang, B.; Zhao, J.; Zhao, J.; Stanton, C.; Ross, R.P.; Zhanga, H.; Chen, W. A ropy exopolysaccharide producing strain Bifidobacterium longum subsp. longum YS108R alleviates DSS-induced colitis by maintenance of the mucosal barrier and gut microbiota modulation. Food Funct. 2019, 10, 1595-1608.

38. Salazar, N.; Gueimonde, M.; de los Reyes-Gavilán, C.G.; Ruas-Madiedo, P. Exopolysaccharides produced by lactic acid bacteria and bifidobacteria as fermentable substrates by the intestinal microbiota. Crit. Rev. Food Sci. Nutr. 2016, 56, 1440-1453. [CrossRef]

39. López, P.; González-Rodríguez, I.; Sánchez, B.; Gueimonde, M.; Margolles, A.; Suárez, A. Treg-inducing membrane vesicles from Bifidobacterium bifidum LMG13195 as potential adjuvants in immunotherapy. Vaccine 2012, 30, 825-829. [CrossRef]

40. Lee, H.A.; Kim, H.; Lee, K.W.; Park, K.Y. Dead Lactobacillus plantarum Stimulates and Skews Immune Responses toward T helper 1 and 17 Polarizations in RAW 264.7 Cells and Mouse Splenocytes. J. Microbiol. Biotechnol. 2016, 26, 469-476. [CrossRef]

41. Xie, N.; Wang, Y.; Wang, Q.; Li, F.R.; Guo, B. Lipoteichoic acid of Bifidobacterium in combination with 5-fluorouracil inhibit tumor growth and relieve the immunosuppression. Bull. Cancer 2012, 99, E55-E63. [CrossRef] [PubMed]

42. Grangette, C.; Nutten, S.; Palumbo, E.; Morath, S.; Hermann, C.; Dewulf, J.; Pot, B.; Hartung, T.; Hols, P.; Mercenier, A. Enhanced antiinflammatory capacity of a Lactobacillus plantarum mutant synthesizing modified teichoic acids. Proc. Natl. Acad. Sci. USA 2005, 102, 10321-10326. [CrossRef] [PubMed]

43. Kim, H.G.; Lee, S.Y.; Kim, N.R.; Lee, H.Y.; Ko, M.Y.; Jung, B.J.; Kim, C.M.; Lee, J.M.; Park, J.H.; Han, S.H.; et al. Lactobacillus plantarum lipoteichoic acid down-regulated Shigella flexneri peptidoglycan-induced inflammation. Mol. Immunol. 2011, 48, 382-391. [CrossRef] [PubMed]

44. Kim, J.Y.; Kim, H.; Jung, B.J.; Kim, N.R.; Park, J.E.; Chung, D.K. Lipoteichoic acid isolated from Lactobacillus plantarum suppresses LPS-mediated atherosclerotic plaque inflammation. Mol. Cells 2013, 35, 115-124. [CrossRef]

45. Segers, M.E.; Lebeer, S. Towards a better understanding of Lactobacillus rhamnosus GG-host interactions. Microb. Cell Fact. 2014, 13 (Suppl. 1), S7. [CrossRef] 
46. Claes, I.J.; Lebeer, S.; Shen, C.; Verhoeven, T.L.; Dilissen, E.; De Hertogh, G.; Bullens, D.M.; Ceuppens, J.L.; Van Assche, G.; Vermeire, S.; et al. Impact of lipoteichoic acid modification on the performance of the probiotic Lactobacillus rhamnosus GG in experimental colitis. Clin. Exp. Immunol. 2010, 162, 306-314. [CrossRef]

47. Claes, I.J.; Segers, M.E.; Verhoeven, T.L.; Dusselier, M.; Sels, B.F.; De Keersmaecker, S.C.; Vanderleyden, J.; Lebeer, S. Lipoteichoic acid is an important microbe-associated molecular pattern of Lactobacillus rhamnosus GG. Microb. Cell Fact. 2012, 11, 161. [CrossRef]

48. Riehl, T.E.; Alvarado, D.; Ee, X.; Zuckerman, A.; Foster, L.; Kapoor, V.; Thotala, D.; Ciorba, M.A.; Stenson, W.F. Lactobacillus rhamnosus GG protects the intestinal epithelium from radiation injury through release of lipoteichoic acid, macrophage activation and the migration of mesenchymal stem cells. Gut 2019, 68, 1003-1013. [CrossRef]

49. Wang, S.; Ahmadi, S.; Nagpal, R.; Jain, S.; Mishra, S.P.; Kavanagh, K.; Zhu, X.; Wang, Z.; McClain, D.A.; Kritchevsky, S.B.; et al. Lipoteichoic acid from the cell wall of a heat killed Lactobacillus paracasei D3-5 ameliorates aging-related leaky gut, inflammation and improves physical and cognitive functions: From C. elegans to mice. Geroscience 2019. [CrossRef]

50. Shiraishi, T.; Yokota, S.; Fukiya, S.; Yokota, A. Structural diversity and biological significance of lipoteichoic acid in Gram-positive bacteria: Focusing on beneficial probiotic lactic acid bacteria. Biosci. Microbiota Food Health 2016, 35, 147-161. [CrossRef]

51. Kim, C.H. Immune regulation by microbiome metabolites. Immunology 2018, 154, 220-229. [CrossRef] [PubMed]

52. Ríos-Covián, D.; Ruas-Madiedo, P.; Margolles, A.; Gueimonde, M.; de Los Reyes-Gavilán, C.G.; Salazar, N. Intestinal Short Chain Fatty Acids and their Link with Diet and Human Health. Front. Microbiol. 2016, 7, 185. [CrossRef] [PubMed]

53. Vinolo, M.A.; Rodrigues, H.G.; Nachbar, R.T.; Curi, R. Regulation of inflammation by short chain fatty acids. Nutrients 2011, 3, 858-876. [CrossRef] [PubMed]

54. Flint, H.J.; Duncan, S.H.; Scott, K.P.; Louis, P. Links between diet, gut microbiota composition and gut metabolism. Proc. Nutr. Soc. 2015, 74, 13-22. [CrossRef] [PubMed]

55. Smith, P.M.; Howitt, M.R.; Panikov, N.; Michaud, M.; Gallini, C.A.; Bohlooly, -Y.M.; Glickman, J.N.; Garrett, W.S. The microbial metabolites, short-chain fatty acids, regulate colonic Treg cell homeostasis. Science 2013, 341, 569-573. [CrossRef] [PubMed]

56. Berni Canani, R.; Di Costanzo, M.; Leone, L. The epigenetic effects of butyrate: Potential therapeutic implications for clinical practice. Clin. Epigenetics 2012, 4, 4. [CrossRef]

57. Furusawa, Y.; Obata, Y.; Fukuda, S.; Endo, T.A.; Nakato, G.; Takahashi, D.; Nakanishi, Y.; Uetake, C.; Kato, K.; Kato, T.; et al. Commensal microbe-derived butyrate induces the differentiation of colonic regulatory $\mathrm{T}$ cells. Nature 2013, 504, 446-450. [CrossRef]

58. Thorburn, A.N.; Macia, L.; Mackay, C.R. Diet, Metabolites, and “Western-Lifestyle” Inflammatory Diseases. Immunity 2014, 40, 833-842. [CrossRef]

59. Trompette, A.; Gollwitzer, E.S.; Yadava, K.; Sichelstiel, A.K.; Sprenger, N.; Ngom-Bru, C.; Blanchard, C.; Junt, T.; Nicod, L.P.; Harris, N.L.; et al. Gut microbiota metabolism of dietary fiber influences allergic airway disease and hematopoiesis. Nat. Med. 2014, 20, 159-166. [CrossRef]

60. Kim, M.H.; Kang, S.G.; Park, J.H.; Yanagisawa, M.; Kim, C.H. Short-chain fatty acids activate GPR41 and GPR43 on intestinal epithelial cells to promote inflammatory responses in mice. Gastroenterology 2013, 145, 396-406. [CrossRef]

61. Tan, J.; McKenzie, C.; Vuillermin, P.J.; Goverse, G.; Vinuesa, C.G.; Mebius, R.E.; Macia, L.; Mackay, C.R. Dietary Fiber and Bacterial SCFA Enhance Oral Tolerance and Protect against Food Allergy through Diverse Cellular Pathways. Cell Rep. 2016, 15, 2809-2824. [CrossRef]

62. Ishikawa, T.; Nanjo, F. Dietary cycloinulooligosaccharides enhance intestinal immunoglobulin A production in mice. Biosci. Biotechnol. Biochem. 2009, 73, 677-682. [CrossRef] [PubMed]

63. Tan, J.; McKenzie, C.; Potamitis, M.; Thorburn, A.N.; Mackay, C.R.; Macia, L. The role of short-chain fatty acids in health and disease. Adv. Immunol. 2014, 121, 91-119.

64. Venkatesh, M.; Mukherjee, S.; Wang, H.; Li, H.; Sun, K.; Benechet, A.P.; Qiu, Z.; Maher, L.; Redinbo, M.R.; Phillips, R.S.; et al. Symbiotic bacterial metabolites regulate gastrointestinal barrier function via the xenobiotic sensor PXR and Toll-like receptor 4. Immunity 2014, 41, 296-310. [CrossRef] [PubMed] 
65. Zelante, T.; Iannitti, R.G.; Cunha, C.; De Luca, A.; Giovannini, G.; Pieraccini, G.; Zecchi, R.; D'Angelo, C.; Massi-Benedetti, C.; Fallarino, F.; et al. Tryptophan catabolites from microbiota engage aryl hydrocarbon recept or and balance mucosal reactivity via interleukin-22. Immunity 2013, 39, 372-385. [CrossRef] [PubMed]

66. Haase, S.; Haghikia, A.; Wilck, N.; Müller, D.N.; Linker, R.A. Impacts of microbiome metabolites on immune regulation and autoimmunity. Immunology 2018, 154, 230-238. [CrossRef] [PubMed]

67. Wlodarska, M.; Luo, C.; Kolde, R.; d’Hennezel, E.; Annand, J.W.; Heim, C.E.; Krastel, P.; Schmitt, E.K.; Omar, A.S.; Creasey, E.A.; et al. Indoleacrylic Acid Produced by Commensal Peptostreptococcus Species Suppresses Inflammation. Cell Host Microbe 2017, 22, 25-37. [CrossRef]

68. Gostner, J.M.; Becker, K.; Kofler, H.; Strasser, B.; Fuchs, D. Tryptophan Metabolism in Allergic Disorders. Int. Arch. Allergy Immunol. 2016, 169, 203-215. [CrossRef]

69. King, N.J.; Thomas, S.R. Molecules in focus: Indoleamine 2,3-dioxygenase. Int. J. Biochem. Cell Biol. 2007, 39, 2167-2172. [CrossRef]

70. Hirata, S.I.; Kunisawa, J. Gut microbiome, metabolome, and allergic diseases. Allergol. Int. 2017, 66, 523-528. [CrossRef]

71. Kepert, I.; Fonseca, J.; Müller, C.; Milger, K.; Hochwind, K.; Kostric, M.; Fedoseeva, M.; Ohnmacht, C.; Dehmel, S.; Nathan, P.; et al. D-tryptophan from probiotic bacteria influences the gut microbiome and allergic airway disease. J. Allergy Clin. Immunol. 2017, 139, 1525-1535. [CrossRef] [PubMed]

72. Gao, J.; Xu, K.; Liu, H.; Liu, G.; Bai, M.; Peng, C.; Li, T.; Yin, Y. Impact of the Gut Microbiota on Intestinal Immunity Mediated by Tryptophan Metabolism. Front. Cell. Infect. Microbiol. 2018, 8, 13. [CrossRef] [PubMed]

73. Douillard, F.P.; de Vos, W.M. Biotechnology of health-promoting bacteria. Biotechnol. Adv. 2019, 37, 107369. [CrossRef] [PubMed]

74. Hidalgo-Cantabrana, C.; Goh, Y.J.; Pan, M.; Sanozky-Dawes, R.; Barrangou, R. Genome editing using the endogenous type I CRISPR-Cas system in Lactobacillus crispatus. Proc. Natl. Acad. Sci. USA 2019, 116, 15774-15783. [CrossRef]

75. Cross, K.L.; Campbell, J.H.; Balachandran, M.; Campbell, A.G.; Cooper, S.J.; Griffen, A.; Heaton, M.; Joshi, S.; Klingeman, D.; Leys, E.; et al. Targeted isolation and cultivation of uncultivated bacteria by reverse genomics. Nat. Biotechnol. 2019, 37, 1314-1321. [CrossRef] 